\title{
English Tense Teaching in Junior High School Based on Prototype Theory-Taking the Simple Present Tense as an Example
}

\author{
Lei Guo \\ School of Foreign Languages and Literatures, Chongqing Normal University, Chongqing, China \\ Junhua Wang \\ School of Foreign Languages and Literatures, Chongqing Normal University, Chongqing, China
}

\begin{abstract}
Simple present tense, an indispensable part of grammar, is the first tense that junior high school students need to grasp in China. In fact, the time things happen does not always correspond with the speech time. Therefore, in the process of teaching, there are some difficulties which would exert great negative influence on students' understanding of tense. There are five usages of simple present tense: state, habitual, instantaneous, past and future usage. On the basis of the prototype theory of categorization, these five usages in simple present tense are all members of this category. Moreover, the present-connectiveness, as the family resemblance, combines these five usages into the present tense category. It is necessary and meaningful for teachers to integrate prototype theory with tense-teaching. In other words, teachers can help students establish a network system which holds all usages of this tense. It can greatly ease students' burdens in comprehension and memory with the forms and usages of the simple present tense. Eventually, the teaching efficiency can be improved to some extent.
\end{abstract}

Index Terms - simple present tense, prototype theory, family resemblance, tense-teaching

\section{INTRODUCTION}

English tense, as an important part of grammar, has been studied by many linguists and grammarians. Teaching tense is the key point of grammar-teaching. Just as the simple present tense represents the current time, the past tense describes something happened in the past and the future tense refers to the events will happen in the future. However, there are some special usages that cannot be explained clearly and distinguished easily in this way. For example, simple present tense is not only used to express something happens at present, it can also refer to something happened in the past and will happen in the future. Prototype theory, appeared in the 1970s, can be applied in tense-teaching. It can be considered that all the usages of this tense belong to same category. In the case, prototype category theory would provide more plausible explanations about the usages of tense.

\section{About The Tense}

\section{A. The Definition of Tense}

The term of tense, has been derived from the Latin words "tempus" which means time. Tense is an important part of the grammar. Verbs have many forms that show the time, continuance, completion of any action or state that is expressed by the verb. In fact, tense has been intensively studied by a lot of scholars at home and abroad. Some linguists believe it is through the role of tense that we can have a better understanding of the correlation between the verb form and our cognition to the specific time presenting in the past or future as well as present. Zhang Daozhen (2001) argues that tense indicates different finite verb forms showing the time of actions or events.

Through the comprehensive comparison and analysis of the English tense, it can be concluded that time is the content of tense, and tense is the grammatical form of time.

Although there are some differences between the scholars' views, they basically hold that tense is in the category of grammar and it can be combined with time to convey the multiple meanings and functions of the verb.

\section{B. The Importance of Tense-teaching in English Teaching}

Teaching tense is essential and cannot be ignored in English teaching. For one thing, tense can help students master four basic skills of English, namely, listening, speaking, reading and writing. Listening and reading are the skills of input. Speaking and writing are the skills of output. The effective and comprehensible output also requires the correct usage of tenses, because correct usage of tenses helps students communicate with others precisely and improves students' writing proficiency.

English and Chinese differ dramatically in expressing time and time relationships with events. Owing to the negative 
transfer of mother tongue, Chinese students are inclined to make mistakes easily when they learn English tense. In fact, the forms of Chinese verb are always the same. To express different forms and time relationships with events, Chinese often add “着、了、过” which follow at the end of the verbs, while a native speaker of English uses different forms of verb to express the time relations. Tense teaching becomes more essential to help the students make fewer mistakes in the process of learning English in China. Additionally, tense is complicated, there are a lot of infinite forms of single verb in English. For example, "take" doesn't only have the forms of "took, takes, taking, taken, will take" but also the forms of "is taking, has been taking, have been taking, was taking". Such multi-forms of a word make it difficult for students to master all usages of tense. Therefore, for Chinese students, tense-teaching is a hard nut to crack. Without tense-teaching, students would make some mistakes which will hinder their efficiency of learning. Therefore, much importance should be attached to the tense-teaching.

\section{Problems With Tense-Teaching In Middle Schools}

\section{A. Too Much Emphasis on Communicative Ability, But Undue Attention to Grammatical Rules}

Nowadays, many English teachers value the communicative ability of students while ignoring the grammatical knowledge. CLT is popular in China. However, there are many teachers who cannot grasp the real meaning of this teaching method and some of them think grammar is of little importance. In practice, they provide a multiple of communicative chances for students but rarely mention the usages of tense in class. If one student can fluently speak with others and give responses naturally, teachers will deem that their teaching aims are achieved. Students cannot produce completely correct sentences because lacking of sufficient grammar knowledge. In a sense, a learner cannot avoid making mistakes concerning the grammar. Thus, paying more attention on grammar teaching is essential to the students' English learning.

\section{B. Teacher's Incorrect Recognition of Tense}

Students' learning efficiency greatly depends on teachers. English teachers have to get a good understanding of tenses so that students can learn it with less effort. It's widely observed that quite parts of teachers misunderstand that the function of tense is to denote time just as what they have learned before. And for a long time, they have had such a wrong understanding of tense which would naturally have a bad influence on students' tense-learning. Unfortunately, teachers would meet some special usages of tenses, namely, time does not always correspond to tense. In that case, teachers would explain them as "fixed usage" and ask students recite these rules at the same time. In fact, teachers cannot completely convince students because they cannot accept such an explanation, which leads to the bewilderment of students after learning. When students do some exercises, they are often confused because not all questions can be solved by the rules they recited. What's worse, it also brings one potential threat that students would be bored with tense learning. Above all, teacher's incorrect recognition of tense would have negative effects on students.

\section{Students' Incorrect Recognition of Tense}

Actually, many junior school students can remember the basic usages of tense which is not difficult for them. However, they cannot appropriately master all usages of tense in some certain contexts because they lack cognitive abilities. For example, students cannot choose the right form of verbs in doing the multiple-choice exercises and there are many forms of verb that they cannot distinguish. Under this situation, students are often confused about the tense and mistakenly understand the tense. It is caused by their incorrect recognition of tenses. Students believe that tenses are only used to describe time and the forms of the verb, and it has to correspond with the time. The reason of this may be related to the development of students' cognitive competence. They often memorize the rules and forms of the tense, but they are not capable to reorganize a model of the tense or classify the usages of tenses. Gradually, students have difficulty in telling the correct form of verb from similar ones, which directly leads to their poor mastery of tense.

\section{THEORETIC FRAMEWORK: Prototype THEORY}

\section{A. The Introduction to the Prototype Theory}

The word of category stems from the Greek and means "identify". It is related to the concept of categorization. Ungerer \& Schmid (2008) argues that the mental process of classification is now commonly called categorization, and its products are categories. Categorization refers to the human's ability to categorize or judge whether a thing is the instance of a particular category or not and this ability has become an indispensable aspect of our cognition. From this view, we can get the view that categorization exists in human beings' daily life and it is a good approach for us to classify concrete things as well as abstract things. Category theory, as an important theory of cognitive linguistics, dates back to the philosophy. Aristotle, the advocator of classic theory, deems that there is a clear boundary in different categories and different entities are classified into a category according to their commonness.

In the last decades, there are more scholars who explored the theory of category and they made some findings in the light of some experiments. In 1953, the anthropologist Ludwig Wittgenstein put forward the principle of family resemblance. In the 1970s, the famous American psychologist Rosch who first brought forward the terminology "prototype" that provides plentiful evidences for the future research. As far as prototype theory is concerned, it holds 
that all members of a category may be related to one another without all members having any properties in common that define the category (Ungerer \& Schmid, 2008). The boundary of categories is fuzzy and all members of one category have different statuses. Some of them may share all or most attributes of category which are called prototype while others are less typical even marginal or peripheral.

Above all, the prototype category theory is studied by the scholars all the time and it does make great contribution to the development of society. In fact, human beings can use the prototype theory to classify different entities in the world. At the same time, the process of cognition of the language is similar to the non-verbal concepts, so it can be assumed that language can also be studied by using this theory.

\section{B. The Analysis of Simple Present Tense in the Sight of Prototype Theory}

In 1978, Rosch pointed out that all the categories established by human beings are, in fact, prototypical categories. The grammatical categories, as a member of man-made categories, should be prototypical. In fact, there is one person, Taylor who has analyzed the usages of the past tense in a cognitive way in 2001. It is obvious that we can analyze the simple present tense based on the corpus in the cognitive way.

According to the BNC (British National Corpus), there are about 60 contexts with the usage of simple present tense. By analyzing the corpus, the most frequently used one is the state usage which is also the prototypical one.

Eg1: The moon turns round the earth.

Eg2: The sun rises in the east.

Eg3: He is a boy.

From the above sentences, it is known to us that this usage often describes the objective facts or states. Actually, these facts or truths stand for one kind of state that could continue all the time and would never be changed as time goes by. It is true all the time, no matter in the past, at present or in the future. It is certain that the actions happened in the past, and can continue in the future beyond the present time. In the first example, moon turns round the earth, this state holds the speech time. At the point of speaking, the moon is turning around the earth. So, it is quite obvious that the event time coincides with the speech time even though it is not restricted. According to Rosch, "each item has at least one, and probably several, elements in common with one or more other items" (Rosch, 1975: P.575). In the third example, when the speaker talks and he was a boy in the past and he will be a boy in the future. From the perspective of cognitive linguistics, the state usage is the prototype in the category of simple present tense because it has many family resemblances and all share some similar attributes of this category. The state usage, easy to master, is used by people frequently so it is in the central position of this category.

Indeed, there are several usages of simple present tense except state usage. According to the BNC, they are listed depending on the frequency of their usage. It is worth of attention that these usages can be classified into the non-prototypical category. It doesn't mean that they are different completely. On the contrary, there are some links or similarities between them. There are some examples:

1. Habitual usage of the simple present tense

Eg1: He walks to school every day.

Eg2: Mrs. Simpson regularly goes to church on Sunday.

From these two examples, it is clear that it is similar to the state usage. To some extent, the speaking time is not in accord with the event or action time. In the first example, "going to school by foot" is his habit and it doesn't mean that he walks to school only at the speaking time. In the second example, it means that Mrs. Simpson goes to church other than Sundays, maybe he went to the church in the past and he will go to the church in the future. Therefore, the action time cannot correspond to the speaking time. Comrie claims that "sentence with habitual meaning not only refers to a sequence of situations recurring at intervals, but rather to a habit, a characteristic situation that holds all at times" (Comrie, 2005: P.39). Indeed, the action of going to church is not always happening on the speaking time, it is also true in the past and future. However, it should be admitted that the action is consistent with the time when the speaker meets Mrs. Simpson who is on the way to the church. From this perspective, it can be consumed that the habitual usage of simple present tense has some attributes shared by prototype although there are some differences. It is the member of the usage of the simple present tense category.

2. Instantaneous usage of the simple present tense

More specifically, it is used for actions in a time which are happening now, the present point of time. Thus, the following sentences can be good examples: (1) I declare the meeting open. (2) I pronounce you man and wife. (3) I sentence you ten-year imprisonment. (4) Michael passes the ball to Tim. Tim moves out to 3-point range, he shoots. In the first sentence, it means the action of "open" happens when the speaker speaks. In the second sentence, this is the declaration of a priest on wedding. And the third sentence, this comes from the judge. As for the last one, it is the saying of a sports commentator. In fact, these sentences are used rarely in human's daily life. Above all, these sentences all describe the event or action occurring at the present moment, namely, the time that speaker speaks. So this kind of usage is transient. It is clear that the present tense basically expresses something which happens at the present time. From this point, it can be said that the instantaneous usage shares some attributes of the state usage. On the basis of this analysis, the instantaneous usage shows the intimate link with the action and the present time. More importantly, it can be concluded that the instantaneous usage should belong to this category.

3. Past usage of the simple present tense 
According to BNC, simple present tense is often used in the state and habitual contexts, but it can also refer to events or actions which happened in the past time in practice. There are some examples as following:

Eg1: Alice tells me you're entering college next year.

Eg2: I hear poor old Mrs. Smith has lost her son.

In these two examples, verbs are "tells" and "hear" instead of using "told" or "heard", which is a little bit difficult to understand. In fact, it is the special usage of the simple present tense. In the first sentence, the speaker just repeats what Alice said. The action "you enter college" will happen in the next year and it is not conform to the speaking time. In the second sentence, "my hearing of Mrs. Smith has lost her son" happens earlier than "my retelling of this event". In fact, the event time isn't accord accordance with the speech time. It is obvious that this phenomenon can be analyzed from the cognitive perspective. It is can be said that it is related to the speaker's psychological distance. In other words, the speaker speaks with this tense out of his own purpose. The speaker can shorten the distance between the event and his performance of speaking in this way. Apparently, this event leaves an unforgettable impression on the speaker, so the speaker wants to make the listener or the reader easily experience the event which happened in the past. It can make them feel that the scene is truthful and vivid. Not surprisingly, it seems that this usage shares little similarity with the prototypical usage of simple present tense, the state usage can also refer to the event happened in the past as "The sun rises in the east". And it also has the present-connectiveness in some degree. At this point, the historic usage also belongs to the category of simple present tense although it is not the best examples of this category.

4. Future usage of the simple present tense

Undoubtedly, simple present usage can also indicate the event which will happen in the future, it is the special usage as the historical usage.

(1) The train leaves at 6:30, so we have enough time to prepare.

(2) If it rains tomorrow, the sports meeting will be canceled.

We can learn that the event time is after the present moment from the first sentence. But here is "leaves" rather than "leaving", the train doesn't leave at the speech time. Many grammarians think that is often used in some contexts in which the event must happen and hardly be changed. It is the plan or the arrangement which was arranged in advance. In the second example, it is clear that there comes a conjunction "if", which introduces adverbial clauses of condition. In such sentences, some events might happen or might be true. In tomorrow, it will be rainy. But one thing we have to notice is that future tense will be used in the main clause of this context. On account of such reasons, this point becomes difficult to teach and learn. Although the event time isn't in accord with the speech time in these contexts, there are some similarities with the state usage, it also has family resemblance and it is the bad examples of this category.

Above all, the simple present tense is analyzed from the cognitive view. The simple present tense is basically used to refer states or at present which is easy to understand. Learner can master this kind of usage at first. It is not surprising that state usage is the prototype of this category, while there are four usages of simple present tense which are non-prototypical. In these four usages, habitual and instantaneous usages have some similarities with the state usage, and they are good examples of this category. Besides, the past and future usages seem to be bad examples. It can be said that they are the special usages of the simple present tense, in which the event time has no direct link with the speech time. It seems that they are hard to grasp. Although they are different from the prototypical usage, they have some similarity with the state usage and are the bad examples of this category.

\section{The Application of Prototype Theory in Teaching Simple Present Tense}

From the 1980s, cognitive linguistics has become popular in English. And many scholars deem that it can be used in teaching vocabulary, reading, listening and grammar. However, it is a question need to explore that how to put the prototype category theory in the practical tense teaching in junior high school. In fact, there are two aspects of teaching tense, which are all of vital importance, one is the form of the simple present tense, and the other is the meaning and the usage of it.

\section{A. Teaching the Form of Simple Present Tense}

It is mentioned that the form and the tense are not consistent, but we have to recognize that the forms of the simple present tense are crucial. Without it, students cannot know the frame of this tense; they cannot describe the things or something they want to express. There are two forms of the simple present tense, the first one is "be", including three forms, "am, is, are". Although they would be used in different contexts, they are all in a network or a category. "be" is the super-ordinate category of "am, is, are". Students often make some mistakes when they do exercises. For example, many students tend to use "be" in some sentences, "There be 40 students in the class". Thus, it shows that students are inclined to memorize the basic form of the simple present tense while neglecting how to change "be" into "am, is, are" in different sentences. For one thing, it is caused by students' carelessness. For another, it is because their cognitive ability is in a low level in junior school. English teachers can do something to improve students' learning ability. The explanation of the form should be valued and the way of explanation should be changed. Teachers could take the cognitive view when they teach the usage of "be". "Am, is, are" are the subordinate of "be", but these four words are not the same. This way would be beneficial to students' cognition, so that they can understand that "am, is, are" are not separated but have some similarities. Importantly, they should be used in different contexts. 
Another one is the verb, including auxiliary and notional verbs, namely, "do" or "verb". In reality, this is the most difficult point for students to grasp. The third person singular is involved in the usage of verbs in the simple present tense. Junior high school students often forget to change the form of verbs. English teachers can also explain to students by taking the category theory. "do" is the simple form and "does" is the variant of "do". Although they are different in some degree, they are in the same category. If teachers can introduce the basic form, students can find a lot of variants of this form then master these forms with less effort. In addition, Teachers' own recognition should be changed. They have to ask students to understand the basic form of the simple present tense because the prototypical form is easy for students to understand and remember. To conclude, category theory, as an effective way, can be adopted by teachers when they teach the forms of the simple tense.

\section{B. Teaching Meaning and the Usages of Simple Present Tense}

From section 4.1, we know that teaching the form of simple present tense is important. Simultaneously, the meaning and the usage of this tense are vital, especially the usage. Without the practical usage, the knowledge of the tense cannot be applied and everything would be meaningless. The usage of simple present tense is various, it is necessary to find a way which can provide some useful information for English teachers. According to the prototypical theory, there are some suggestions.

1. Emphasizing the teaching of the basic usage of simple present tense

Now that the usage of the simple present tense can be regarded as a category in which one member is link with another, English teachers can teach simple present tense from this perspective. They can try to help students master the basic usage, i.e. the prototypical usage. This is very important. In section 3.2, the writer analyzes the state usage which is prototypical. In this case, the state exists at present or a longer time, so it is not difficult for students to understand. When teachers explain this kind of usage, they must realize its importance. In practical teaching, the teacher can ask students to grasp this usage firstly. Undoubtedly, teachers must focus on the state usage in teaching. They also should tell the students that the state usage is basic which can provide some help for the following learning. At the beginning of the tense teaching, teachers had better not introduce other complicated usages of this tense. In brief, teachers are supposed to develop students' consciousness that state usage is the center of this category - the usage of simple present tense. Based on the state usage, teachers should help students turn to a deeper level. Besides, teachers have to give up the previous ways that students just recite the rules of simple present tense. Reciting rules cannot solve all problems. Only realize the prototypical usage of the tense in contexts that can students grasp the essence of this tense and learn other usages with less efforts.

2. Extending other usage of simple present tense based on prototype

It can be said that there are some ways if the teachers want students master all usages of simple present tense completely. In other words, teachers can improve students' cognitive ability based on the prototypical usage. In the process of tense teaching, teachers can develop students' cognitive ability that could promote their understanding of other usages. In section 3.2, it describes other four non-prototypical usages of simple present tense. Teachers should have a correct recognition of these four uses and they must help students form a correct recognition, too. And they should help learners establish a radical network which includes all usages. From the analysis in section 3.2, we know that habitual usage and the instantaneous usages have more similarities with the prototypical usage. In the past, teachers always ask students remember these rules mechanically, which is futile. Teachers can help students develop their own rules system by establishing the category system. So the teachers can take advantages of this point. For example, they can explain the similarities between these three usages and compare the differences in the process of teaching, so that students can have a clear understanding. The habitual usage and instantaneous usage are the best examples in this category and they have some similar attributes, so students can learn them easily based on the prototypical usage.

Definitely, the past and the future usage of the simple present are also the members of this category although they are bad examples. Explaining these two usages is not easy and students cannot accept them without confusion. They have one similarity with the prototypical usage - the state usage, so they should be included in this category. Just as mentioned in section 3.2, the past usage includes the speaker's own purpose that he wants to shorten the distance between the event time and the speech time. Teachers should ask students to compare the past usage with the state usage; the state usage can also be used to refer to the previous state. In this respect, they are connected with each other. Although students cannot understand the past usage until the teacher introduce the prototypical usage - state usage, they can connect it with each other. Similarly, the future usage also has some attributes which are involved in the state usage. State usage can refer to the state which exits in the future time so teachers should explain the future usage after teaching the state usage.

All in all, according to the category theory, teachers can find some instructions about how to teach simple present tense from this view. They should emphasize the basic usage of this tense at first. Then, based on the prototypical usage, they can help students establish a system that other four usages can be learned. Consequently, students can learn the simple present tense with less efforts and the teaching efficiency can also be improved.

\section{CONCLUSION}

This paper introduces tense, the importance of tense-teaching and the problems of it in junior high school. These 
problems are connected with several factors: teacher's overemphasis of communicative ability, teacher's incorrect recognition of tense and students' incorrect recognition of tense. This paper analyzes the simple present tense from a new perspective - prototype category theory and finds out the family resemblance of all the members of this category. The various usages of the simple present tense have a similar attribute: they are all present-connective although some are direct, some are not. Based on the prototype category theory, there come some useful instructions which are beneficial to tense-teaching. In practical tense-teaching, forms and the usages of the tense are of equal importance. Teachers can help students grasp the basic form of simple present tense, and then students can understand the variants of the prototypical form. When teaching the usage of this tense, it would be better to help students construct a category network which holds all usages of the simple present tense. Thus, students can master the simple present tense completely with less effort and the teaching efficiency can also be improved. However, there are some deficiencies and limitations in this paper, further studies on this topic need to be carried out in the future.

\section{REFERENCES}

[1] Comrie, B. (2005). Tense. Beijing: Beijing University Press, 2005.

[2] John Eastwood. (2011). Oxford Practice Grammar. Beijing: Foreign Language Teaching and Research Press.

[3] Li Yanping. (2011). A Theoretical View of Prototype in English Grammar Teaching. Foreign Language Education, 3, 62-64.

[4] Taylor, J, R. (2001). Linguistics Categorization: Prototypes in Linguistics Theory. Beijing: Beijing University Press.

[5] Ungerer, F. \& Schmid, H. J. (2008). An Introduction to Cognitive Linguistics. Beijing: Foreign Language Teaching and Research Press.

[6] Wang Yin \& Li Hong. (2003). Prototype theory and differences of word-formation between English and Chinese. Foreign Language and Literature, 3, 135-136.

[7] Zang Zhenbang. (2001). A New English Grammar Coursebook. Shanghai: Shanghai Foreign Language Education Press.

[8] Zhang Daozhen. (2001). A Practical English Grammar. Beijing: Foreign Language Teaching and Research Press.

Lei Guo was born in Sichuan, China in 1995. Now, he is a postgraduate student in linguistics in Chongqing Normal University, China. His research interests include foreign language teaching and cognitive linguistics.

Junhua Wang was born in Nanchong, China in 1995. She is currently a postgraduate in the School of Foreign Languages, Chongqing Normal University, Chongqing, China. Her research interests include second language acquisition and English teaching. 